\title{
ОСОБЕННОСТИ ВЗАИМОСВЯЗИ ЗРИТЕЛЬНОГО ВОСПРИЯТИЯ И НАГЛЯДНО-ОБРАЗНОГО МЫШЛЕНИЯ У МЛАДШИХ ШКОЛЬНИКОВ С РАЗНЫМИ ТИПАМИ ОНТОГЕНЕЗА
}

\begin{abstract}
Аннотация. Предметом исследования являются особенности зрительного восприятия и наглядно-образного мышления в восприятии сюжетных картин у детей младшего школьного возраста при разных типах онтогенеза. В статье представлен теоретический анализ развития зрительных функций и наглядно-образного мышления у детей младшего школьного возраста при разных типах онтогенеза. В современной психологической литературе по диагностике психического развития ребёнка значительное внимание уделяется изучению зрительного восприятия и наглядно-образного мышления, как предпосылок успешного обучения. Таким образом, становится актуальным исследование взаимосвязи зрительного восприятия и наглядно-образного мышления учащихся в общеобразовательной школе детей, имеющих различные нарушения психической деятельности в связи с наличием у них разных медицинских диагнозов, например: «минимальная мозговая дисфункция» (ММд), и "расстройства аутистического спектра» (РАС). Методологической основой данного исследования являются современные представления отечественной психологии о закономерностях формирования высших психических функций, разработанные Л.С. Выготским и А.Р. Лурией, с учетом неравномерности их развития в онтогенезе и механизмах нарушения представленных в нейропсихологическом подходе. Традиционными методами диагностики высших психических функций являются методы нейропсихологической диагностики, позволяющие обратиться к сравнительному анализу сформированности разных высших психических функций.

Впервые описана взаимосвязь зрительного восприятия и наглядно-образного мышления, выделена типология ошибок и их влияние на понимание смысла сюжетных картинок у детей младшего школьного возраста при разных типах онтогенеза. Проведённое исследование выявило дефрицитарность зрительного восприятия при нормальном онтогенезе ММД и РАС, которое оказывает влияние на наглядно-образное мышление. Следовательно, при наличии дефицита зрительного восприятия, наглядно-образное мышление не всегда может служить опорой в разных видах учебной деятельности. Данные результаты позволили выявить "мишени» для коррекционно-развивающей работы педагогов-психологов с детьми младшего школьного возраста.

Ключевые слова: сравнительный анализ, наглядно-образное мышление, зрительное восприятие, высшие психические функции, онтогенез, нейропсихология детского возраста, младшие школьники, минимальные мозговые дисфункции, расстройства аутистического спектра, трудности обучения.

Review. The subject under research is the peculiarities of visual perception and visual thinking demonstrated by primary school students with different ontogenesis when perceiving genre paintings. The article contains the theoretical analysis of visual functions and visual thinking of primary school students with different ontogenesis. New psychological literature on diagnostics of child's mental development focuses extensively on visual perception and visual thinking as the prerequisites for successful education. Thus, it is becoming an urgent issue to study the relation between visual perception and visual thinking of school students with different mental impairments as a result of medical diagnoses such as minimal brain dysfunction and autism spectrum. The methodological basis of the research involves contemporary views of Russian psychologists on the objective laws of the development of higher mental functions described by Lev Vygotsky and Alexander Luria taking into account the unevenness of their development during ontogenesis as well as the mechanisms of mental impairments described by the neuropsychological approach. Traditional methods of diagnostics of the higher mental functions are the methods of neuropsychological diagnostics allowing to perform the comparative analysis of the level of the development of particular higher mental functions. This is the first research in the academic literature to describe the re-
\end{abstract}




\section{Клиническая психология}

lation between visual perception and visual thinking, to create a classification of mistakes and to discuss the influence of these mistakes on the level of understanding of genre paintings by primary school students with different ontogenesis. As a result of the research, Shal' has found out that children suffering from minimal brain dysfunction and autism spectrum with normal ontogenesis have a deficiency of visual perception which has an impact on visual thinking, too. Consequently, visual thinking does not always support teaching activities where there is the deficiency of visual perception. These results have allowed to define the 'targets' for corrective measures of school psychologists working with primary school children.

Keywords: primary school age, learning disabilities, representational thought, comparative analysis, active visual perception, higher mental functions, pediatric neuropsychology, ontogenesis, minimal brain dysfunction, autism spectrum.

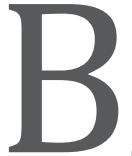
нашей стране в последние два года в системе образования уделяется серьёзное внимание в отношении отдельных категорий детей с ограниченными возможностями здоровья, с реализацией принципов инклюзивного (интегративного) образования. Эта новая система образования предполагает возможность обучения детей с особенностями развития в общеобразовательной массовой школе. В связи с этим становится актуальной проблемой обучения в общеобразовательной школе детей, имеющих различные нарушения психической деятельности в связи с наличием у них разных медицинских диагнозов, например: «минимальная мозговая дисфункция» (ММД), и «расстройства аутистического спектра» (РАC).

В современной психологической литературе по диагностике психического развития ребёнка значительное внимание уделяется изучению зрительного восприятия и наглядно-образного мышления, как предпосылок успешного обучения. Основной особенностью наглядно-образного мышления является способность дифференцировать между собой план реальных предметов и образов, отражающие эти объекта, когда имеется возможность произвольной актуализации детьми этих образов и выстраивание системы новых образов. Наглядно-образное мышление является генетически ранней формой мышления и конструируется на основе практического познания окружающих объектов через создание образных представлений о предметах манипуляций.

Анализ литературных источников обнаруживает тесную взаимосвязь гностических и мыслительных процессов в наглядно-образном мышлении, при этом их отношения не зависят от их параллельности или взаимоперехода друг в друга, важнейшим показателем мыслительной деятельности при этом является процесс смыслообразования, дифференциации качеств и отношений перцептивного образа. Используется понятие «образной логики» $[1$, с. 84], где происходит объединение разрозненных, противоречивых признаков ситуации вокруг смыслового ядра в одно целое. Дано определение одного из условий развития наглядно-образного мышления предполагающего способность дифференцировать между собой план реальных, конкретных предметов, данных в окружающей действительности и образы или модели, отражающие эти объекты: Основная линия развития наглядно-образного мышления, заключается в формировании умений оперировать образами предметов или их частей. В качестве основы такого оперирования выступает умение детей произвольно актуализировать эти образы [2, с. 256].

Отмечается зависимость интеллектуально-познавательной деятельности младших школьников от развития образного мышления в педагогическом процессе, при этом сама динамика его становления связывается со способностью конструировать и выделять целостные предметные образы, восприимчивостью к осмыслению многоаспектности явлений, обобщенностью частных представлений, обращённостью к способу действий и гибкостью, вариативностью образов [3, с. 158]. Тем не менее, остаются недостаточно изученными механизмы взаимосвязи зрительно восприятия и наглядно-образного мышления, как при нормальном онтогенезе, так и при различных типах дизонтогенеза.

В практической работе психолога в интеграционной школе в ситуации нейропсихологической диагностики детей достаточно часто выявляется дефицитарность зрительного восприятия и наглядно-образного мышления, которая проявляется в учебной деятельности детей с различными особенностями функционирования центральной нервной системы (нормальный онтогенез и дизонтогенез) в виде полноценного или ограниченного усвоения учебного материала и приводит к разному уровню успеваемости. В связи с этим необходима качественная диагностика, позволяющая выявить особенности развития психической деятельности детей младшего школьного возраста с разным типом онтогенеза.

С позиций нейропсихологического подхода 
зрительное восприятие является активным процессом поиска требуемой информации, выделения существенных признаков, сличения их между собой и исходными данными [4, с. 232]. Зрительное восприятие формируется в онтогенезе достаточно продолжительный период, заканчивая своё формирование в старшем подростковом возрасте, где активно формируется один из компонентов гностической сферы, а именно регуляция самого процесса восприятия [5, с. 9]. На основе активного зрительного восприятия происходит обработка информации, поступающей из внешней среды, которая включает идентификацию объекта, установление взаимосвязи между пространственным расположением объектов. Для реализации наглядно-образного мышления необходимо извлечение из памяти соответствующих образов предметов или явлений в их взаимосвязи. Эти же компоненты входят в состав наглядно-образного мышления (HOM), обеспечивая выделение причинно-следственных связей и формирования адекватного ответа.

В нашем экспериментальном исследовании была поставлена задача проанализировать уровень сформированности гностической сферы и её влияние на реализацию наглядно-образного мышления у детей младшего школьного возраста (3-5 классы) с разным типом онтогенеза.

\section{Методы}

Исследование наглядно-образного мышления проводилось на основе восприятия, понимания и последующего формирования рассказа по одноактной сюжетной картинке «Разбитое окно» (методика № 1), которая является традиционной методикой, используемой в нейропсихологии и серии из трех сюжетных картинок «Лягушки спрятались» (методика № 2) из книги Н. Радлова «Рассказы в картинках» [6, с. 116]. Предъявляемая серия сюжетных картин, предназначенная для детского возраста, является материалом, доступным для его понимания детьми младшего школьного возраста.

Начальным этапом наглядно-образного мышления при восприятии серии сюжетных картин, является первичное симультанное (одномоментное), а затем сукцессивное (последовательное) зрительное восприятие, осуществляющее выделение значимых элементов сюжета, при сопоставлении которых возникает формирование первичной гипотезы, затем осуществляется последовательное активное отслеживание изменений, происходя- щих с этими значимыми объектами или деталями на трех картинках. Происходит последовательное восприятие стимульного материала и передача поэтапного развития сюжета, при этом возникает целеполагание, т.е. выделяется цель, ради которой осуществляются все промежуточные этапы разворачивающейся ситуации. Одновременно отбрасываются (оттормаживаются) ярко выраженные детали сюжета, которые не вписываются в смысловое содержание сюжета. Вся эта активная зрительно-аналитическая деятельность воплощается в речевую форму, в рамках которой происходит установление причинно-следственных связей.

В эксперименте участвовало 80 детей, учащихся 3-5 классов интеграционной школы № 1321 «Ковчег» с разными типами онтогенеза. По имеющимся диагнозам дети распределились на 3 группы: 1-группа «норма» (13 человек), 2-группа детей с диагнозом «минимальная мозговая дисфункция» (ММД) (46 детей), 3-группа - с диагнозом «расстройства аутистического спектра» (РАC) (21 ребёнок).

\section{Результаты исследования}

В рассказе подсчитывалось количество ошибок в зрительном восприятии, наличие адекватной гипотезы, установление причинно-следственных связей, необходимых для полного отражения последовательности событий. Результаты обрабатывались с помощью качественно-количественного анализа, традиционного для нейропсихологии.

Под трудностями в зрительном восприятии мы понимаем наличие ошибочных ответов при составлении рассказа, связанных с неточностью восприятия элемента картинки, пропусков значимых деталей и установление ошибочных взаимосвязей между элементами сюжета. Была выделена следующая типология ошибок (курсивом отмечены ответы детей):

1. Пропуск значимых элементов в сюжетах;

2. Собственно гностические ошибки (например: подросток-«бабушка», разбитое стекло«цветок», «волосы», носки-«змеи», кепка«улитка»);

3. Формальное восприятие, которое выступает в виде перечисления элементов без установления взаимосвязи между объектами и установления взаимосвязи между элементами из-за близкого их пространственного расположения, например, «мужчина разбил окно рукой», «цапля клюет одежду». 


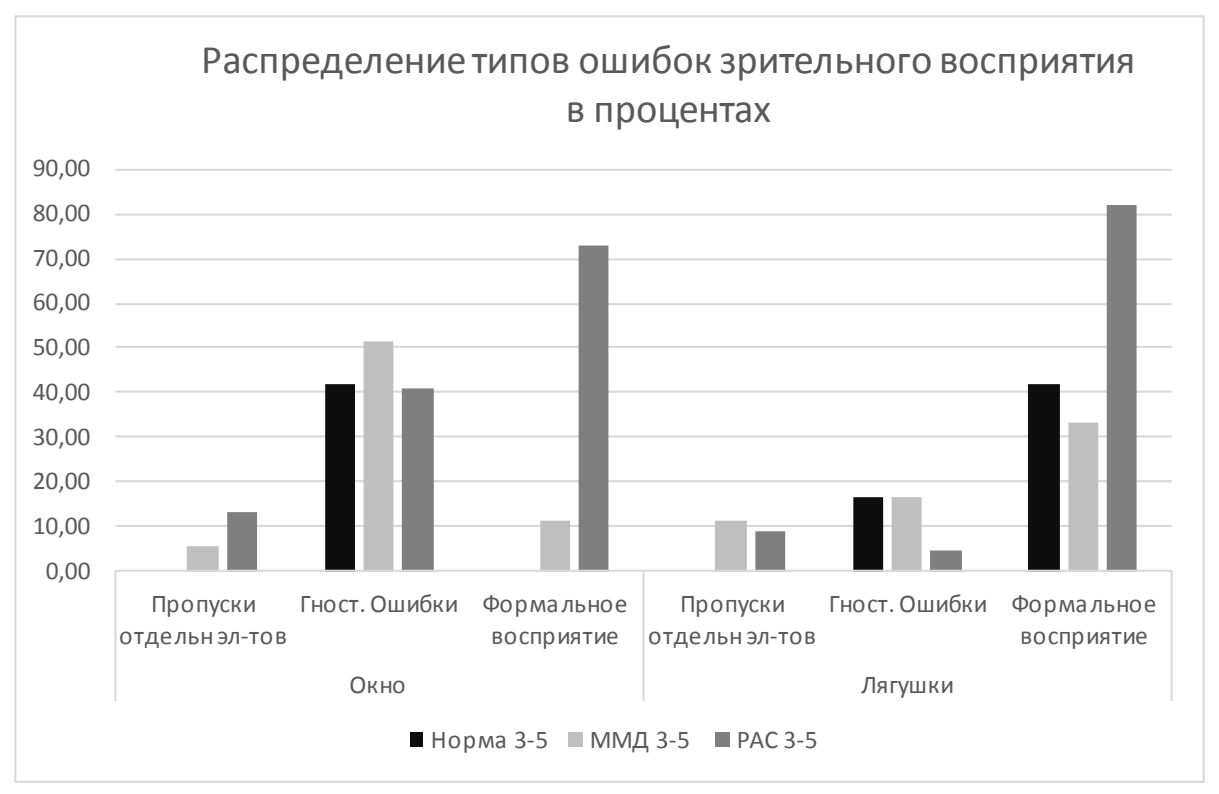

Диаграмма № 1.

\section{Анализ результатов}

Результаты по двум методикам выявляют наличие ошибок зрительного восприятия во всех трех экспериментальных группах, что свидетельствует о том, что гностические функции находятся в стадии формирования у данного контингента детей.

В методике № 1 в группе детей с нормальным онтогенезом в младшем школьном возрасте выявляются гностические ошибки у 41,7 \% детей, эти ошибки проявляются в трудностях опознания отдельных элементов и персонажей сюжетной картинки, например «мальчик, который спрятался за деревом» воспринимается как «мама», «бабушка», или «снежок» воспринимается как «мяч» или как «камень», т.е. без учёта времени года. Наличие данных ошибок не приводит к трудностям понимания основных событий сюжета, но при этом в целом рассказы становятся менее реалистичными. В данной группе отсутствуют ошибки по типу пропусков и формального восприятия, дети этой группы воспринимают все элементы сюжета и составляют развернутый рассказ по сюжетной картинке. От первой ко второй методике у детей с нормальным онтогенезом выявляет наличие двух типов ошибок, допускаемых детьми: гностические ошибки в 16,7 \% случаев и формальное восприятие, которое встречается у 41,7 \% детей. Гностические ошибки связаны с трудностями вербально-перцептивного характера, так правильно воспринимая одежду мальчика, ученица 4 класса, показывая на «ботинки», обозначает их «перчатками». Ошибки по типу формального восприятия возникают у детей при интерпретации сюжетной картинки, когда устанавливается взаимосвязь между элементами изза их близкого пространственного расположения, например, у испытуемой И.Б. 3 класс: «Аист решил утащить одежду».

Полученные результаты графически представлены в диаграмме № 1 .

Для детей с ММД в младшем школьном возрасте характерно наличие всех трех типов ошибок. Так пропуски отдельных элементов допускают $5,6 \%$ детей, гностические ошибки встречаются у 51,4 \%, что несколько выше, чем в группе детей с нормальным онтогенезом. Гностические ошибки, допущенные детьми этой группы несколько отличаются от ошибок детей с нормальным онтогенезом, так например: «окно» воспринимается как «разбитая картина», «мужчина»-«дед с закрытыми глазами», «мальчик со снежком»-«бабушка, которая кидала во внука». Ошибки по типу формального восприятия выявляются у 11,1 \% детей. Для детей с ММД в первой возрастной подгруппе в методике № 2 характерно наличие всех трех типов ошибок. Так пропуски отдельных элементов допускают 11,4 \% детей. В основном дети пропускают значимый элемент «лягушки», что приводит к неправильному пониманию сюжета. Гностические ошибки встречаются у $16,7 \%$, что соответствует 
количеству детей нормальным онтогенезом первой возрастной подгруппы. Данные ошибки, допущенные детьми этой группы, несколько отличаются от ошибок детей с нормальным онтогенезом, так например: «носки» воспринимаются как «змея», кепка-«медальон». Ошибки по типу формального восприятия выявляются у 43,2 \% детей, они аналогичны ошибкам в группе детей с нормальным онтогенезом.

В группе детей с ММД по сравнению с «нормой», в целом, отсутствуют выраженные различия в количестве детей допускающих ошибки зрительного восприятия. Различия наблюдаются только в отношении отдельных видов ошибок.

У детей группы РАС в младшем школьном возрасте в методике № 1 выявляется высокий процент детей, демонстрирующих ошибки в зрительном восприятии. У них выявляются все три типа ошибок: ошибки по типу пропусков (13\%), у несколько большего процента детей отмечаются гностические ошибки (41 \%), не встречающиеся во всех других группах, например: «осколки стекла» воспринимаются как «треугольнички» и наиболее выражен процент детей, допускающих ошибки по типу формального восприятия (72,7 \%). В методике № 2 отмечается увеличение процента детей с формальным восприятием (81,8 \%), при этом выявляется небольшой процент детей с пропусками $(8,7 \%)$ и гностическими ошибками $(4,6 \%)$. Т.е. при возможности опознания элементов сюжета дети с расстройствами аутистического спектра при составлении рассказа по сюжетным картинкам ограничиваются перечислением значимых элементов сюжета без попыток установления взаимосвязи между ними у них.

Проанализируем возможности установления детьми причинно-следственных связей, на основе зрительного восприятия, когда их полнота соответствует адекватному пониманию смысла сюжетных картин. Невозможность или частичное установление причинно-следственных связей приводит к трудностям понимания, часто сочетающееся с выделением неадекватных причинно-следственных связей. Неадекватные причинно-следственные связи представляют собой всегда противоречащую изображенному сюжету фиксацию определённых отношений между элементами и персонажами, возникающую на основе зрительного восприятия и приводящую к возникновению побочных ассоциаций. В некоторых случаях неадекватные причинно-следственные связи полностью замещают адек- ватные, а в некоторых случаях имеется сочетание адекватных и неадекватных причинно-следственных связей. При анализе текстов мы выделяли как количество правильно установленных причинноследственных связей (ПСС), так и количество неадекватных ПСС. В ряде случаев у одного ребёнка при составлении устного рассказа наряду с правильными причинно-следственными связями, актуализировались и неадекватные ПСС, поэтому мы считали проценты как правильных ПСС, так и неадекватных для группы в целом.

Рассмотрим более подробно установление причинно-следственных связей детьми разных экспериментальных групп в двух методиках.

В методике № 1 («Разбитое окно») для полноценного понимания сюжета картинки «Разбитое окно» должны быть выделены две адекватные причинно-следственные связи:

1. Виновник разбил и спрятался,

2. Наказывают невиновного, потому что первым попался на глаза.

Для полноценного понимания серии сюжетных картин («Лягушки спрятались») необходимо выделение четырех причинно-следственных связей:

1. Лягушки полезли в носки, чтобы спрятаться,

2. Лягушки полезли в носки от аиста,

3. Мальчик поднял руки, потому что удивился (испугался),

4. Мальчик удивился, потому что носки изменили положение.

Для сюжета «Разбитое окно» «полное понимание» соответствовало установлению обеих ПСС, а «неполному» пониманию соответствовало одной ПСС. Для сюжета «Лягушки «полное» понимание рассматривалось как установление трех и четырех причинно-следственных связей, «неполное» понимание как установление 2 и менее связей, но для дальнейшего сопоставления гностических трудностей разного типа и ПСС, анализировалось только полное понимание.

Необходимо отметить, что во всех экспериментальных группах в методике № 2 по сравнению с методикой № 1 снижается процент детей, выделяющих все причинно-следственные связи, и отмечается увеличение процента детей, формирующих неадекватные ПСС. Это связано с самим стимульным материалом, так как в данной методике присутствует большее количество элементов сюжета, а значит и возрастает возможность различной трактовки вследствие определённой «провокации» на ошибку. 


\section{Клиническая психология}

Младшие школьники с нормальным онтогенезом полностью устанавливают причинно-следственные связи в 92,3\% случаев и только 7,7\% испытывают трудности. Примером такого затруднения может служить рассказа ученика 5 класса С.И.: «Короче вот этот пацан кинул в окно снежком и разбил его. Выбежал мужик и походу поведет его в милицию. А другой спрятался за деревом, может, повезёт он ему в рожу кинет снежок и спасет его. Кто здесь ещё есть? Тетка какая-то из окна выглядывает очкастая. Нахальная рожа этот просит спасти, а тот может не спасти». В данном примере мальчик изначально не правильно установил взаимосвязи между элементами сюжета, сделав смыслообразующим ядром рассказа, ситуацию в центре и остальные элементы уже встраиваются в сюжет в соответствии с логикой рассказчика. В методике № 2 полностью устанавливают причинноследственные связи 81,6 \% детей и частичное установление ПСС доступно 15,4 \%, также в этой группе у 15,4 \% выявляются неадекватные причинно-следственные связи. Возникновение неадекватных причинно-следственных связей в данной подгруппе связано с трудностями ориентации при восприятии сюжета, но при разворачивании сюжета и повышения активности зрительного восприятия дети этой группы приходят к правильному пониманию и выделяют все ПСС. Примером такого затруднения может служить рассказа ученика 4 класса П.Е.: «Мальчик пошел купаться оставил свои вещи на берегу, все развесил, все повесил, он не обращал внимания на свои вещи, а когда купался, то услышал какие-то звуки, либо аист, либо та, которая лягушек ест в болоте, она взяла и утащила, она, по-моему, промочила все его носки бросила их в воду, он на неё ругается, а она веселится или что-то в этом роде. Кто здесь ещё есть? Здесь лягушки ещё присутствуют, лягушки залезли в носки и поползли в воду, испугались птицу, они в носках». Рассказывая сюжетную картинку, ученик вначале не замечает «лягушек» и выстраивает причинно-следственные связи на основе воспринятых элементов, небольшая организующая стимуляция со стороны психолога, приводит к изменению сюжета и правильной интерпретации.

В группе детей с минимальной мозговой дисфункцией при восприятии сюжетной картинки «Разбитое окно» отмечается меньший процент детей, по сравнению с группой «норма», полностью установивших причинно-следственных связи $(60,9 \%)$. Частичное установление ПСС доступно 28,2 \% детей, не устанавливает ни одной ПСС
10,9 \% детей и неадекватные причинно-следственные связи устанавливает $13 \%$.

При составлении рассказов по серии сюжетных картинок «Лягушки спрятались» отмечается меньший процент детей, по сравнению с методикой № 1, полностью установивших причинно-следственные связи (43,5\%), частичное установление ПСС доступно $37 \%$ школьникам, при этом резко повышается процент детей формирующих неадекватные причинно-следственные связи 43,5 \% и не устанавливает ни одной ПСС 19,5 \% детей. Примерами неадекватных ПСС в данной группе служат следующие высказывания детей: «Журавль стоит, хочет позвать мальчика, что бы он остановил лягушек, вытащил их из носок и выпустил в воду», «Мальчик поднял руки, что бы попросить цаплю, что бы она его не клевала». Данные примеры отличаются от группы «норма» формальным восприятием элементов сюжета, большей нереалистичностью, где аист наделяется антропоморфными качествами. Такие варианты ответов могут указывать на наличие воображения, при трудностях истинного понимания смысла картинок, в качестве компенсации.

В младшем школьном возрасте меньшему проценту детей с РАС в сюжетной картинке «Разбитое окно» доступно установление всех причинно-следственных связей по сравнению с группой «норма» (14,3 \%), частично устанавливает ПСС 28,6 \% детей. В данной возрастной группе 57,1\% школьников не устанавливает ПСС и у 33,3 \% детей выявляются неадекватные причинно-следственные связи. При составлении рассказов в методике № 2 также выявляется низкий процент детей полностью установивших причинно-следственные связи (4,8 \%), частичное установление ПСС доступно 33,3 \%. В данной возрастной группе выявляется высокий процент детей, не установивших ни одной ПСС (61,9\%) и у 33,3 \% школьников выявляются неадекватные причинно-следственные связи. Для детей с РАС характерен достаточно низкий процент детей, устанавливающих адекватные причинно-следственные связи, в сочетании с высоким процентом детей, которые либо не устанавливают адекватных связей, либо выделяют неадекватные связи. Они формируют вычурные гипотезы, не отражающие реальных взаимосвязей между элементами сюжета. Примеры таких гипотез: «лягушатки в носочки залезли, чтобы мальчик босиком пошел», «Мальчик увидел журавля, журавль что-то съел и его вырвало», «Пришел аист, начал кричать и начал 


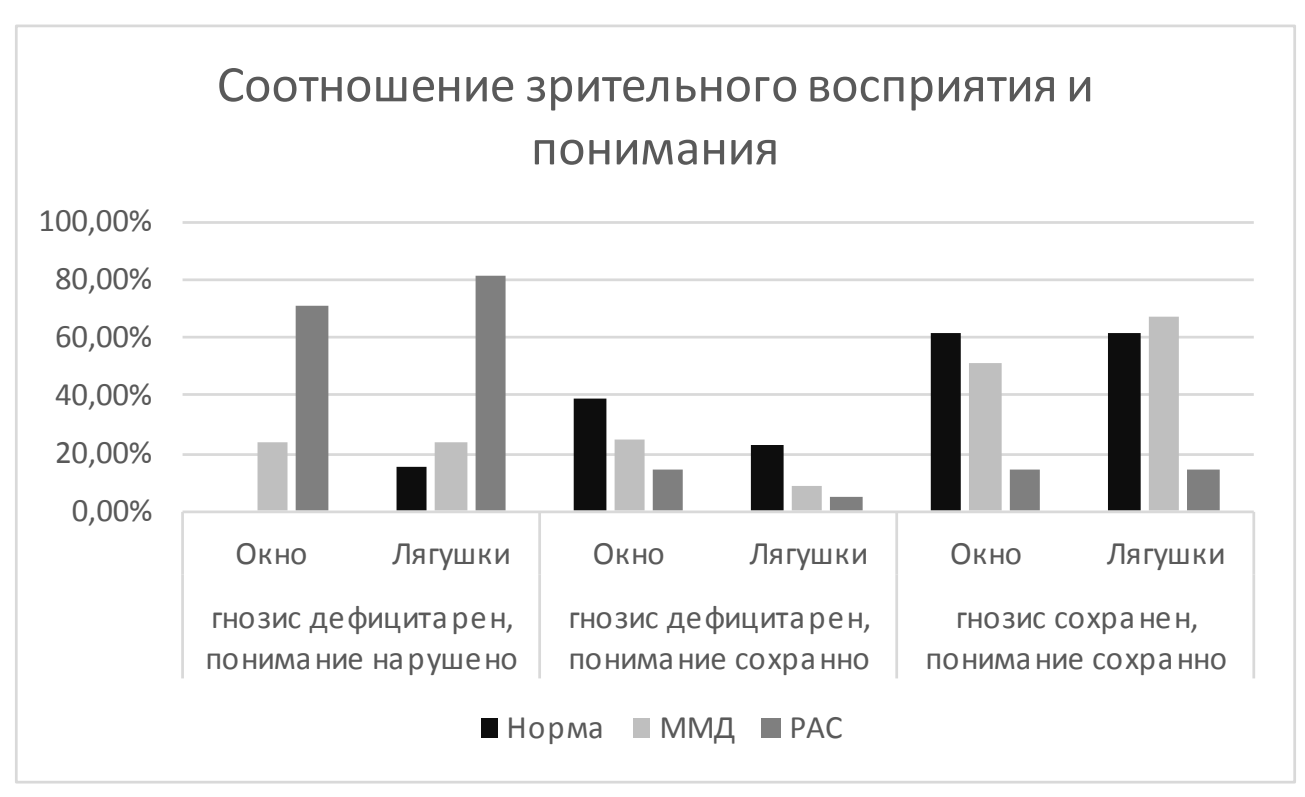

Диаграмма № 2.

гнать мальчика из озера. Зачем? Это аистово озеро, не понравилось, что кто-то в его озере». "В носках забрались, сидят лягушки. Зачем? Потому что они прыгуны, и они были любопытные вот и полезли».

Таким образом, ошибки зрительного восприятия приводят к трудностям формирования причинно-следственных связей, а, следовательно, оказывают влияние на понимание смысла сюжета, что проявляется в дефицитарности наглядно-образного мышления.

Рассмотрим влияние ошибок в зрительном восприятии на понимание смысла сюжетных картин в одноактной сюжетной картинке и по серии сюжетных картин.

Полученные результаты графически представлены в диаграмме № 2 .

В группе детей с нормальным онтогенезом в методике № 1 были выявлены 38,5 \% детей с ошибками в зрительном восприятии, при этом у данных детей понимание истинного смысла сюжета оказывается успешным. Примером является рассказ ученика Ш.Д. 4 класс: «На этой картинке мальчик вот этот разбил стекло, а его поймал дяденька, Хулиган-ученик. А на самом деле это был не он, а вот этот мальчик. Он держит в руке мяч, это он разбил. А дяденька поймал не того мальчика, видите он тут прячется». В этом рассказе при наличии гностической ошибки «мяч» вместо «снежка», у ребёнка в процессе изложения смысла сюжета формируется адекватная гипотеза, учи- тываются все объекты и связи между элементами сюжета, что приводит к полному пониманию содержания картинки. В данной возрастной подгруппе не встречается сочетание ошибок зрительного восприятия с неправильным пониманием смысла сюжета.

В методике № 2 у данной группы детей выявляется процент детей с ошибками в зрительном восприятии при понимании истинного смысла сюжета в 23,1 \% случаев. Сочетание ошибок зрительного восприятия с неправильным пониманием смысла сюжета выявляется у 15,4 \% детей.

В группе детей с ММД в младшем школьном возрасте отмечается меньший процент детей, по сравнению с «нормой», у которых выявляются ошибки в зрительном восприятии, сочетающиеся с полным пониманием смысла сюжетной картинки «Разбитое окно» (25\%). В данной группе выявляется 23,9\% детей с ошибками в зрительном восприятии, приводящим к неправильному толкованию картинки. Приведём пример текста ученика 3 класса 3.Г.: «Разбили окно. Шапка лежит на земле. Папа взял сына. Он (сын) разбил окно. Мама сказала сыну: «Это ты разбил окно?» Мама прячется за деревом, подглядывает. Что здесь ещё происходит? Что папа взял сына. Я тоже подглядываю, когда разговаривают. Чтобы новое окно купить стоит 1 миллион долларов». В данном рассказе неправильно воспринятый «мальчик со снежком» как «мама», приводит к возникновению неверных 
гипотез, при этом организующий вопрос не приводит к правильному пониманию картинки, ребёнок придерживается своей первоначальной гипотезы.

При составлении рассказа по серии сюжетных картинок «Лягушки спрятались» у 8,7 \% детей ошибки в зрительном восприятии сочетаются с полным пониманием. А у 23,9\%. детей ошибки в зрительном восприятии приводят к неправильному пониманию. Пример текста ученика 3 класса Б.М.: «Мальчик хотел охладиться, ему очень жарко было. Он увидел речку, снял с себя одежду и оставил плавки. Его увидел Страус. Я не знаю. Цапля увидела его и тоже захотела на речку. Она закричала, напугала его, поэтому он ушел из речки. И она пошла за ним. Что здесь ещё есть? Вещи. 2-ая картинка от 3-ей чем-то отличается? Кружки есть, а здесь не было». В данном рассказе мальчик пропускает «лягушек» и, соответственно, старается выстроить логический рассказ на тех элементах, которые он воспринял. Он выдвигает гипотезы неадекватные содержанию картинки, но являющиеся адекватными в русле его логики, основываясь на воспринятых элементах картинки.

В группе детей с PAC в методике № 1 выявляется небольшой процент детей с ошибками зрительного восприятия при полном понимании сюжета $(4,8 \%)$. Сочетание ошибок зрительного восприятия и непонимания смысла сюжета встречается у $81 \%$ детей. Приведем пример рассказа ученика 3 класса К.Н.: «Дом. Дядя, комочек у него. Дядя взял, вырвал чемоданчик. Они дерутся. Дядя разбил стекло, вот этот вот (с портфелем). Ну, показал, ты разбил стекло. В окне бабушка». В данном тексте присутствуют ошибки по типу «формальное восприятие». Ребёнок устанавливает взаимосвязи между элементами на основе их близкого пространственного расположения (на картинке мальчик с портфелем стоит рядом с окном), что приводит к искажению смысла сюжета.

Аналогичная тенденция выявлена в методике № 2: несколько увеличивается процент детей с ошибками зрительного восприятия при полном понимании сюжета (14,3\%), при этом несформированность зрительного восприятия в сочетании с непониманием остаётся достаточно высокой 71,4 \% детей.

\section{Выводы}

Итак, подводя итоги анализа результатов исследования гностической сферы, можно от- метить в группах детей с нормальным онтогенезом и ММД следующую тенденцию: при нормальном онтогенезе дети младшего школьного возраста демонстрируют значительную дефицитарность гностических функций за счет гностических ошибок при восприятии одноактной сюжетной картинки. В группе ММД встречаются все типы ошибок при восприятии сюжета «Разбитое окно», но они мало влияют на её понимание школьниками. Несмотря на наличие этих ошибок, детям доступно выделение значимых элементов и установление большей части причинно-следственных связей между ними с последующим выдвижением гипотезы в отношении содержания. При восприятии серии сюжетных картин можно выделить наличие гностических трудностей, которые в своём большинстве негативно влияют на понимание смысла сюжета, что связано с увеличением объема воспринимаемого материала на серии сюжетных картин «Лягушки спрятались». У детей обеих групп нарастает количество гностических трудностей, несмотря на стимуляцию извне, активизирующую гностическую деятельность школьников. Наиболее отчетливо это проявляется в значительном росте количества формальных ошибок, при незначительном количестве гностических ошибок.

При расстройствах аутистического спектра в младшем школьном возрасте гностическая сфера является наименее сформированной и максимально дефицитарной в обеих методиках, по сравнению с остальными экспериментальными группами. Для них характерен высокий процент детей, которые выделяют неадекватные причинно-следственные связи, из-за наличия трудностей в гностической сфере, что приводит к выраженным трудностям понимания смысла сюжетных картин, а, следовательно, выраженной дефицитарности нагляднообразного мышления.

Проведенное исследование выявило дефицитарность зрительного восприятия при нормальном онтогенезе ММД и РАС, которое оказывает влияние на наглядно-образное мышление. Следовательно, при наличии дефицита зрительного восприятия наглядно-образное мышление не всегда может служить опорой в разных видах учебной деятельности. Данные результаты позволили выявить «мишени» для коррекционно-развивающей работы педагогов-психологов с детьми младшего школьного возраста. 


\section{Психология и психотехника 7(82) • 2015}

\section{Список литературы:}

1. Гурова Л.Л. Психология мышления. М.: ПЕР СЭ, 2005. 135 с.

2. Поддьяков Н.Н. Мышление дошкольника. М., 1977. 277 с.

3. Прокопова Д.И. Педагогические условия формирования образного мышления младших школьников: Дисс. ... канд. пед. наук. Курс, 2002. 184 с.

4. Лурия А.Р. Основы нейропсихологии. М.: Академия, 2004. 381 с.

5. Ахутина Т.В., Пылаева Н.М. Диагностика зрительно-вербальных функций: учебное пособие. М.: Академия, 2003.60 с.

6. Полонская Н.Н. Нейропсихологическая диагностика детей младшего школьного возраста. М.: Академия, 2007.185 с.

7. Ахутина Т.В., Игнатьева С.Ю., Максименко М.Ю., Полонская Н.Н., Пылаева Н.М., Яблокова Л.В. Методы нейропсихологического обследования детей 6-8 лет // Вестн. Моск. Ун-та. Серия 14. Психология. 1996. № 2. С. 51-58

8. Ахутина Т.В., Пылаева Н.М. Преодоление трудностей учения. Нейропсихологический подход. М.: Изд. центр. «Академия», 2008. 319 с.

9. Выготский Л.С. Собрание сочинений. Т. 6. М., 1983. 369 с.

10. Корсакова Н.К., Микадзе Ю.В., Балашова Е.Ю. Неуспевающие дети: нейропсихологическая диагностика трудностей в обучении. Изд. 2. М.: Педагогическое общество России, 2001. 154 с.

11. Люблинская А.А. Очерки психического развития ребёнка. 2-е изд., перераб. М.: Просвещение, 1965. 361 с.

12. Микадзе Ю.В. Нейропсихология детского возраста. СПб.: Питер, 2008. 284 с.

13. Никольская О.С., Баенская Е.Р., Либлинг М.М. Аутичный ребёнок. Пути помощи. М.: Теревинф, 2010.288 с.

14. Психология аномального развития ребёнка: Хрестоматия в 2 т. / П.р. В.В. Лебединского и М.К. Бардышевской. М.: ЧеРо, Высш. шк., Изд-во МГУ, 2002. Т. 2. 817 с.

15. Сприн О., Таппер Д., Райссер А., Туокко Х., Иджел Д. Минимальная мозговая дисфункция // Хрестоматия по нейропсихологии. М.: Ин-т Об. Исс., 2004. С. 830-834.

\section{References (transliteration):}

1. Gurova L.L. Psikhologiya myshleniya. M.: PER SE, 2005. 135 s.

2. Podd'yakov N.N. Myshlenie doshkol'nika. M., 1977. 277 s.

3. Prokopova D.I. Pedagogicheskie usloviya formirovaniya obraznogo myshleniya mladshikh shkol'nikov: Diss. ... kand. ped. nauk. Kurs, 2002.184 s.

4. $\quad$ Luriya A.R. Osnovy neiropsikhologii. M.: Akademiya, 2004. $381 \mathrm{s.}$

5. Akhutina T.V., Pylaeva N.M. Diagnostika zritel'no-verbal'nykh funktsii: uchebnoe posobie. M.: Akademiya, $2003.60 \mathrm{~s}$.

6. Polonskaya N.N. Neiropsikhologichekskaya diagnostika detei mladshego shkol'nogo vozrasta. M.: Akademiya, 2007.185 s.

7. Akhutina T.V., Ignat'eva S.Yu., Maksimenko M.Yu., Polonskaya N.N., Pylaeva N.M., Yablokova L.V. Metody neiropsikhologicheskogo obsledovaniya detei 6-8 let // Vestn. Mosk. Un-ta. Seriya 14. Psikhologiya. 1996. № 2. S. 51-58.

8. Akhutina T.V., Pylaeva N.M. Preodolenie trudnostei ucheniya. Neiropsikhologicheskii podkhod. M.: Izd. tsentr. «Akademiya», 2008. 319 s.

9. Vygotskii L.S. Sobranie sochinenii. T. 6. M., 1983. $369 \mathrm{~s}$

10. Korsakova N.K., Mikadze Yu.V., Balashova E.Yu. Neuspevayushchie deti: neiropsikhologicheskaya diagnostika trudnostei v obuchenii. Izd. 2. M.: Pedagogicheskoe obshchestvo Rossii, 2001. 154 s.

11. Lyublinskaya A.A. Ocherki psikhicheskogo razvitiya rebenka. 2-e izd., pererab. M.: Prosveshchenie, $1965.361 \mathrm{s.}$

12. Mikadze Yu.V. Neiropsikhologiya detskogo vozrasta. SPb.: Piter, 2008. $284 \mathrm{s.}$

13. Nikol'skaya O.S., Baenskaya E.R., Libling M.M. Autichnyi rebenok. Puti pomoshchi. M.: Terevinf, 2010.288 s.

14. Psikhologiya anomal'nogo razvitiya rebenka: Khrestomatiya v 2 t. / P.r. V.V. Lebedinskogo i M.K. Bardyshevskoi. M.: CheRo, Vyssh. shk., Izd-vo MGU, 2002. T. 2. 817 s.

15. Sprin 0., Tapper D., Raisser A., Tuokko X., Idzhel D. Minimal'naya mozgovaya disfunktsiya // Khrestomatiya po neiropsikhologii. M.: In-t Ob. Iss., 2004. S. 830-834. 